\title{
Centimeter Per Minute
}

National Cancer Institute

\section{Source}

National Cancer Institute. Centimeter Per Minute. NCI Thesaurus. Code C105481.

A unit of both speed (scalar) and velocity (vector), defined as the distance of one

centimeter traveled per unit time equal to one minute. 